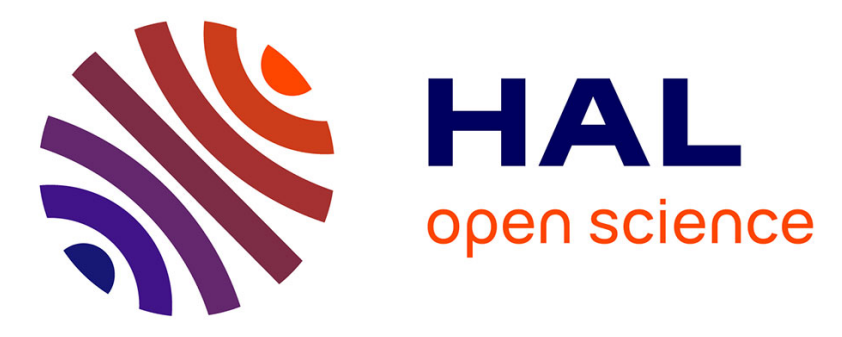

\title{
Robotic microassembly and micromanipulation at FEMTO-ST
}

\author{
Joël Agnus, Nicolas Chaillet, Cédric Clévy, Sounkalo Dembélé, Michaël \\ Gauthier, Yassine Haddab, Guillaume J. Laurent, Philippe Lutz, Nadine Le \\ Fort-Piat, Kanty Rabenorosoa, et al.
}

\section{To cite this version:}

Joël Agnus, Nicolas Chaillet, Cédric Clévy, Sounkalo Dembélé, Michaël Gauthier, et al.. Robotic microassembly and micromanipulation at FEMTO-ST. Journal of Micro-Bio Robotics, 2013, 8 (2), pp.91-106. 10.1007/s12213-013-0065-5 . hal-00801873

\section{HAL Id: hal-00801873 https://hal.science/hal-00801873}

Submitted on 5 Apr 2013

HAL is a multi-disciplinary open access archive for the deposit and dissemination of scientific research documents, whether they are published or not. The documents may come from teaching and research institutions in France or abroad, or from public or private research centers.
L'archive ouverte pluridisciplinaire HAL, est destinée au dépôt et à la diffusion de documents scientifiques de niveau recherche, publiés ou non, émanant des établissements d'enseignement et de recherche français ou étrangers, des laboratoires publics ou privés. 


\title{
Robotic microassembly and micromanipulation at FEMTO-ST
}

\author{
J. Agnus · N. Chaillet ' C. Clévy ' S. Dembélé · M. Gauthier ' Y. Haddab · G. Laurent ' \\ P. Lutz $\cdot$ N. Piat $\cdot$ K. Rabenorosoa $\cdot$ M. Rakotondrabe $\cdot$ B. Tamadazte
}

Received: 1 March 2012 / Accepted: 6 September 2012 / Published online: 9 February 2013

(C) Springer-Verlag Berlin Heidelberg 2013

\begin{abstract}
This paper deals with a historical overview of the activities of the French FEMTO-ST institute in the field of microrobotic manipulation and assembly. It firstly shows tools developed for fine and coarse positioning: 4 DOF microgrippers, 2 DOF modules and smart surfaces. The paper then goes on the automation of tridimensional microassembly of objects measuring between 10 and 400 microns. We are especially focusing on several principles. Closed loop control based on micro-vision has been studied and applied on the fully automatic assembly of several 400 microns objects. Force control has been also analyzed and is proposed for optical Microsystems assembly. At least, open loop trajectories of 40 microns objects with a throughput of 1,800 unit per hour have been achieved. Scientific and technological aspects and industrial relevance will be presented.
\end{abstract}

Keywords Microgrippers · Microassembly · Micromanipulation · Microrobotic automation · MEMS assembly

\section{Introduction}

Until now, miniaturization was driven by a general diminution of the volume of the product (e.g. cell phones). Currently, the major objective of the miniaturization is to

J. Agnus $\cdot$ N. Chaillet $\cdot$ C. Clévy $\cdot$ S. Dembélé $\cdot$

M. Gauthier $\cdot$ Y. Haddab $\cdot$ G. Laurent $\cdot$ P. Lutz ( ) N. Piat .

K. Rabenorosoa $\cdot$ M. Rakotondrabe $\cdot$ B. Tamadazte

Automatic Control and Micro-Mechatronic Systems Department

(AS2M), FEMTO-ST Institute, UMR CNRS 6174 - UFC/ENSMM/

UTBM, 24, rue Alain Savary, 25000 Besançon, France

e-mail: philippe.lutz@femto-st.fr increase the number of functionalities in a product whose volume is mostly constant (e.g. smart phone). In the future, the functions realized using micro or nanotechnologies would be assembled and packaged in order to build integrated multifunctional products or even intelligent products. The hybridization of technologies in micronanosystems is consequently a major stake for the next ten years. The application fields of these future products are typically the networks of sensors for environmental monitoring or the diagnostic and drug delivery done by intelligent systems embedded in human body. Industrial robotics at this scale should be especially studied in order to propose handling, positioning solutions for automatic assembly of these new generation systems. Since 1995, the research team from Besançon, France, has performed significant research activities in the field of micro and nano robotics. These activities were started since in the LAB-laboratory (Laboratoire d'Automatique de Besançon) and are being continued at FEMTO-ST, where the LAB is integrated in 2008 as the AS2M department (Automatic Control and Micro-Mechatronic Systems Department).

FEMTO-ST/AS2M activities deal with the micromanipulation and microassembly issues. More precisely, FEMTOST robotic motions, perception, control and manipulation at the microscale and also new activities at the nanoscale. It corresponds to various and multidisciplinary scientific issues:

- Microrobotic and adaptronic systems: systems for feeding, carrying, gripping, micrometer size and microfabricated robotics, strategies for microassembly. Some examples are in $[9,38,46]$,

- Advanced control of dynamic and complex systems: modelling and control of microactuators microsystems, and smart materials, of discrete or continuous 


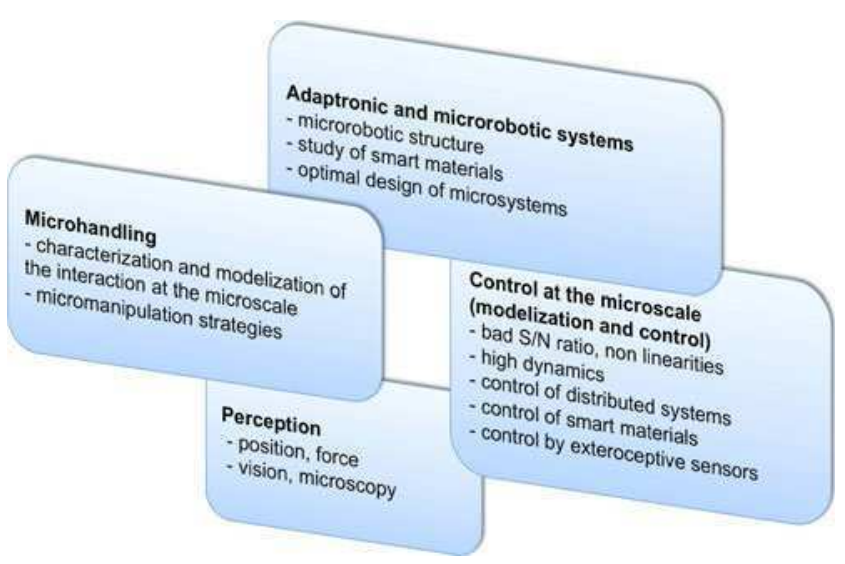

Fig. 1 Major adressed issues studied at FEMTO-ST/AS2M

distributed systems, control by exteroceptive sensors notably by vision. Some examples of our works are given in $[8,18,26,27,33,34,44,47-50]$,

- Micromanipulation and microassembly: characterization of the interactions in the microworld, strategies for microhandling based on physical principles relevant at this scale (the case of the liquid environment has been particularly studied) [21, 23, 25, 39],

- Perception and measurement: measure of microforces and artificial vision $[1,20,52,53]$.

Figure 1 summarizes the major addressed issues studied at FEMTO-ST/AS2M. This paper summarizes the activities of the French institute FEMTO-ST in micromanipulation and micro-assembly. First section is devoted to present some tools for micromanipulation and microassembly which have been developed. In the following section is presented automatic 3D assembly using visual servoing on 400 microns objects. An other way to assemble automatically microparts is to use force control as presented in Section 4. Teleoperation of the assembly of 40 microns objects are detailed in Section 5 before a presentation of the future challenges in micronanoassembly.

\section{Tools for micromanipulation and microassembly}

\subsection{Microgrippers made at FEMTO-ST}

The microgrippers, developed at FEMTO-ST [37], are based on two degrees of freedom (DOF) bimorphs that allow open-and-close motion as well as up-and-down motion (Fig. 2). Each finger is able to move independently from the other in two orthogonal directions. This microgripper, named MMOC (Microprehensile Microrobot On Chip) has therefore 4 DOF and is able to grip, hold and (a) open/close motion

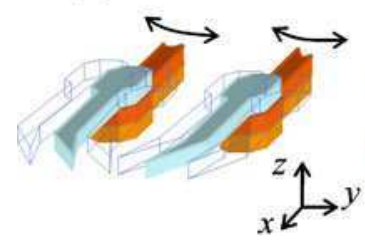

(b) up/down motion

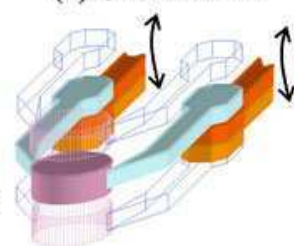

Fig. 2 Mobilities of the microgripper

release submillimetric-sized objects up to several micrometers. The up-and down motion can be useful for fine motion, for release strategies of objects by crossing the fingers or for insertion of microparts and is particularly convenient to align the finger-tips if they are misaligned after the microfabrication processes and assembly.

The principle of one finger is based on a piezoelectric cantilever with local electrode [36], named duo-bimorph (Fig. 3). Such a microgripper presents at the end of the finger tips for $\pm 100 \mathrm{~V}$ a $320 \mu \mathrm{m}$ stroke for open/close motion and a $200 \mu \mathrm{m}$ stroke for up/down motion.

Several packaging have been designed from 2002 to 2012 (Fig. 4): the first one, built to illustrate the 'Microrobot on chip' concept (Fig. 4a) has rapidly given way to a more robust plug-and-use microgripper integrated in a LEMO $^{\circledR}$ connector (Fig. 4b) for micromanipulation of objects which dimensions are between $100 \mu \mathrm{m}$ and $1 \mathrm{~mm}$. The version given in Fig. $4 \mathrm{c}$ has been designed for compactness reasons to embed the microgripper on a KLEINDIECK's robot (MM3) for micromanipulation in a Scanning Electron Microscope (SEM). The last version (Fig. 3d) allows several developments, including finger-tips improvement and integration of position and force sensors. It is able to manipulate objects which sizes are between 10 and $100 \mu \mathrm{m}$.

Beyond its performances and its four degrees of freedom that make this FEMTO-ST microgripper particularly efficient, the success of a micromanipulation is often conditioned by the end-effectors. In most of the microgrippers, actuators and end-effectors are both made on the

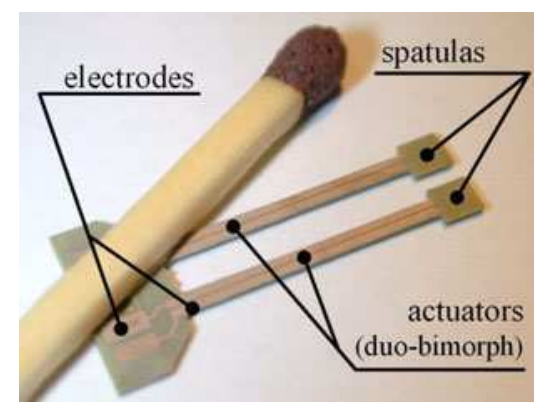

Fig. 3 Piezoelectric actuators of the FEMTO-ST microgripper 


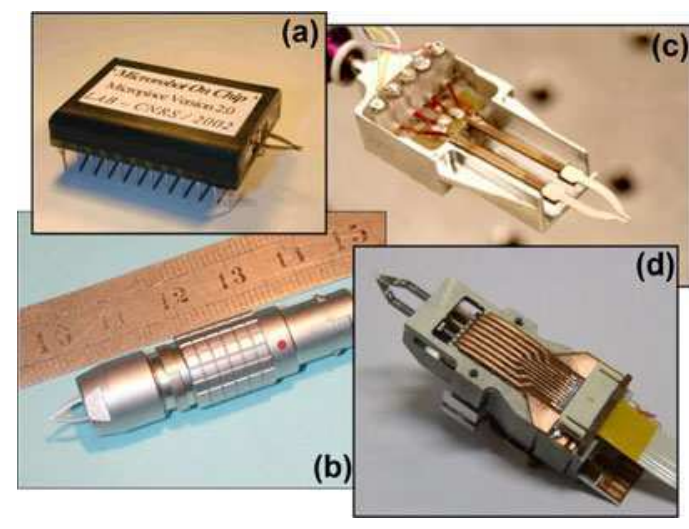

Fig. 4 FEMTO-ST microgrippers along the years

same element. The microgripper developed at FEMTOST is composed of an actuator and a connection system to fix end-effectors. The two piezoelectric actuators have two spatulas (Fig. 3) where different kinds of finger-tips can be fixed. An automated fixing system, with removable thermal glue has already been studied [3]. This microgripper is then particularly flexible to support any end-effector design.

Indeed, the size, the shape, the materials in contact and the environment conditions are some important parameters to achieve a good micromanipulation. These parameters must be adapted to the objects manipulated. The finger-tips material must be also choice for the expected application (conductive finger-tips, transparent, biocompatible, etc.).

We designed several end-effectors to match each application. For instance, the first prototypes were equipped with Nickel finger-tips with $200 \mu \mathrm{m}$ in thickness microfabricated by a LIGA-UV process. Figure 5 shows different shapes. They allowed to easily handle objects between $100 \mu \mathrm{m}$ and more.

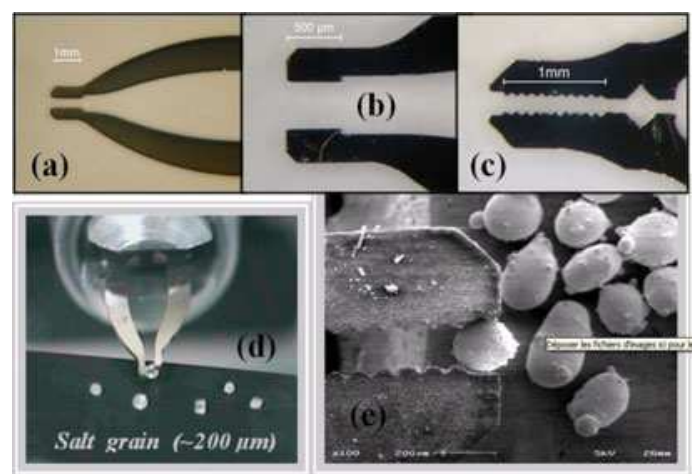

Fig. 5 Nickel finger-tips $(200 \mu \mathrm{m}$ thick $)$

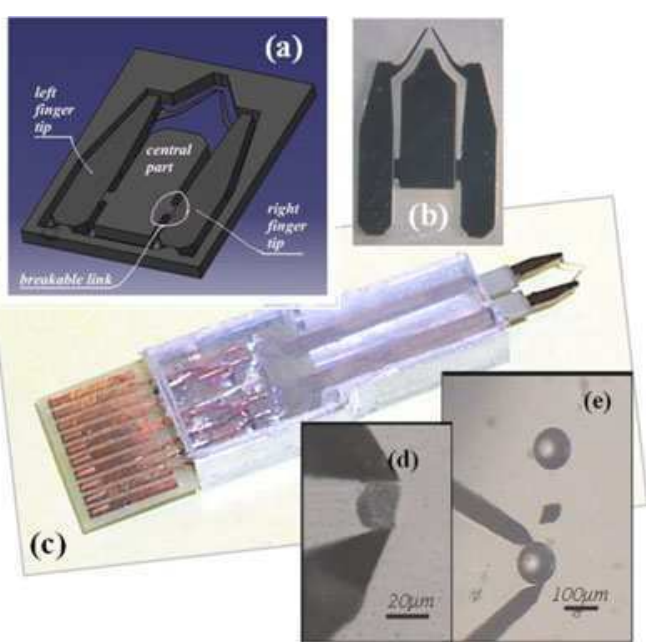

Fig. 6 Silicon finger-tip (10 $\mu \mathrm{m}$ thick $)$

The environment conditions are also critical at this scale because of the complex force gradients due to adhesion forces (surface tension forces, electrostatic forces and Van der Waals atomic forces). Below $100 \mu \mathrm{m}$, many problems arise, especially during the release phase, due to the surface forces between the end-effectors and the manipulated object. Specific silicon end-effectors able to grasp objects between 10 and $100 \mu \mathrm{m}$ have been designed (Fig. 6) [3]. They were microfabricated mainly with DRIE process on SOI wafer with $10 \mu \mathrm{m}$ for the handle thickness. The gap and the alignment of the tips are provided by breakable-parts broke after gluing the pair of fingers on the spatulas of the actuators (Fig. 6a and b). Figure 6d and e show respectively the manipulation of a $20-\mu \mathrm{m}$ silicate grain and $100-\mu \mathrm{m}$ glass sphere.

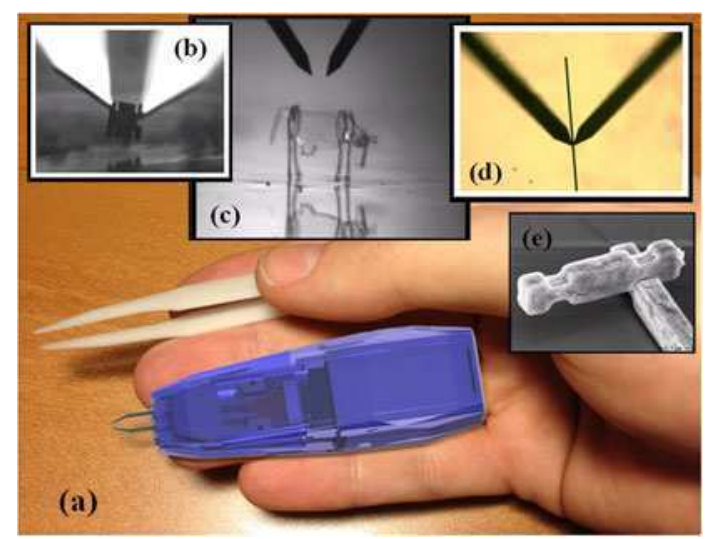

Fig. 7 a PiTweez from Percipio-Robotics, b micromanipulation of a silicon micro part $40 \mu \mathrm{m} \times 40 \mu \mathrm{m} \times 5 \mu \mathrm{m}$, c polymer microcow to demonstrate micro-assembly $(500 \mu \mathrm{m}$ long, smallest nose part is $50 \mu \mathrm{m} \times 50 \mu \mathrm{m} \times 5 \mu \mathrm{m})$, d fiber, $7 \mu \mathrm{m}$ diameter, e silicon parts assembly, $7 \mu \mathrm{m}$ width 
Several research activities in the field of microgripping tools are currently under development concerning in particular some sensorized finger-tips based on piezoresitive effect. It measures grasping forces and enables the control in force and/or position of the fingers, based on self-sensing technique [31, 32]. The presented FEMTO-ST microgripper is now commercially available for purchase at the start-up PERCIPIO RoBOTICS (http://www.percipio-robotics.com) end of the research team. The so-called PiTweez (Fig. 7) is able to mechanically grasp micro parts between $100 \mu \mathrm{m}$ and $1 \mathrm{~mm}$. PERCIPIO-RoBotics proposes various options with high resolution sensors to increase the accuracy of finger positioning or can design any fingers on demand with a great range of materials according to the user needs. For instance, Fig. 8 shows polymer finger-tips designed by PERCIPIO-RoBotics to manipulate objects measuring a few tens of micrometers.

\subsection{The 2 DOF high stroke and high resolution microrobot: TRING-module}

The manipulation and assembly of small components and MEMS may require a system that is able to perform a long distance and a high resolution/precision at the same time. Picking a small component from one location, transporting and placing it in another location for assembly needs that the transportation system have micrometric or submicrometric precision and often more than a ten of millimeters of distance to cover. A way to reach such performances is the use of stepper microrobots often based on stick-slip motion principle. In this section, we present the TRING-module stick-slip microrobot and its use for pick-and-place tasks in microassembly of MEMS at FEMTO-ST.

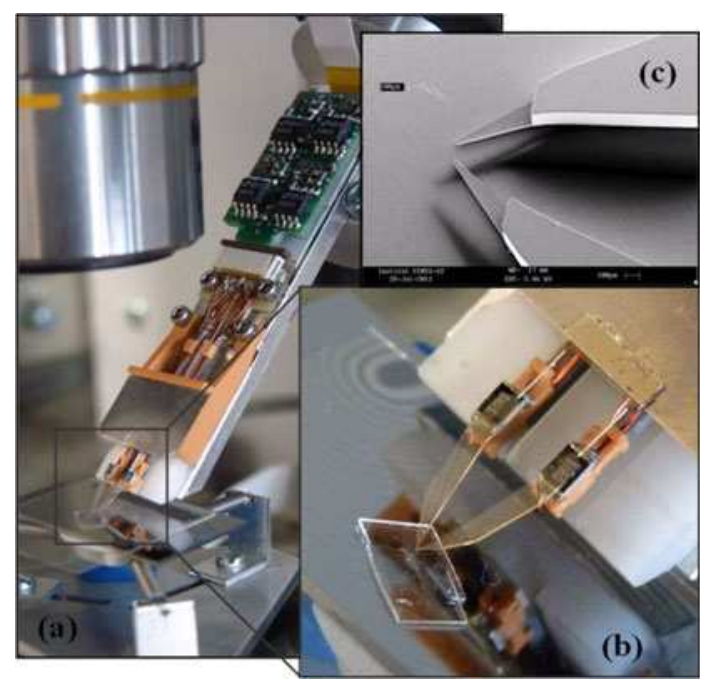

Fig. 8 a PiezoTweeze prototype, $\mathbf{b}$ and $\mathbf{c}$ details of polymer finger-tips

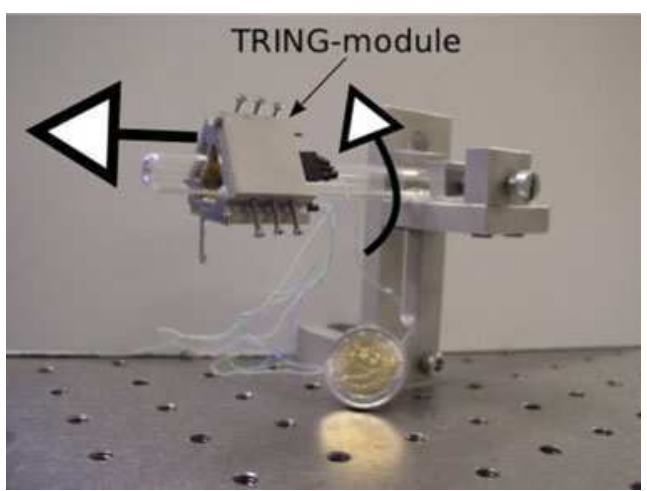

Fig. 9 A photography of the TRING-module stick-slip microrobot

\subsubsection{Kinematic and principle of motion of the TRING-module}

The TRING-module is a microrobot that has 2 DOF: linear motion along the axis of its support and angular motion about the same axis (Fig. 9). The axis that supports the microrobot is a cylindrical glass. A cantilever is placed at the extremity of the TRING-module and is used as endeffector that facilitates the handling of the manipulated objects. Developed in the previous work [46], its principle of movement is based on the stick-slip functioning and uses piezoelectric microactuators described in [7]. The main features of the TRING-module are its theoretical unlimited stroke both in rotation and in translation, the high resolution that it can offer and its good dexterity (rotation and translation).

\subsubsection{Performances of the TRING-module}

As a stick-slip microrobot, the TRING-module can perform the high stroke motion by step-by-step. This is obtained by applying a sawtooth voltage to the piezoelectric microactuators. The speed of the microrobot is proportional to both the frequency $f_{\mathrm{ss}}$ and the amplitude $U_{\mathrm{ss}}$ of the voltage, while the step-magnitude depends principally on the amplitude [45]. The high stroke motion is usually employed for a coarse positioning in a large distance. It is also possible to work within a step (sub-step). This sub-step motion, usually employed for fine positioning, is obtained by applying a voltage with limited slope to the microactuators. In substep motion, the resolution of the TRING-module is greatly amplified, although the limited range of motion. The stepby-step motion and the sub-step motion can be managed and switched automatically by using the closed-loop control law developed in [45]. The principal advantage of the latter control law is the obtention of high speed and high precision at the same time without manual reconfiguration of the controller. 
Table 1 Performances of the TRING-module

\begin{tabular}{llll}
\hline Motion & Step & Max speed & Stroke \\
\hline Linear & $70 \mathrm{~nm} \rightarrow 200 \mathrm{~nm}$ & $2 \mathrm{~mm} / \mathrm{s}$ & Unlimited \\
Angular & $17 \mu \mathrm{rad} \rightarrow 44 \mu \mathrm{rad}$ & $2.4 \mathrm{rpm}$ & Unlimited \\
\hline
\end{tabular}

Table 1 summarizes the performances of the TRINGmodule alone without closed-loop control $[45,46]$. It clearly shows the high performances, in particular in term of resolution and stroke, of the microrobot that are well suited to the requirement in microassembly in general.

\subsubsection{Pick-and-place tasks based on two TRING-modules}

To perform pick-and-place tasks in microassembly, the TRING-module can be used in different ways. One of the main interesting ways is to employ two TRING-modules in the same axis. As pictured in Fig. 10, the two microrobots form a microgripper with variable gap between their endeffectors. This scheme allows the manipulation of microobjects and objects of various sizes. Additionally to that, the transport in large distance and with a high resolution is possible thanks to the performances of the microrobots.

In the configuration pictured in Fig. 10, we have proposed to control on force the first TRING-module and to control on position the second one. The main advantage is that additionally to the precise positioning, the manipulation force and the insertion force (during the assembly) are also commanded in such a way that the destruction of the objects is avoided. It also enables the good gripping of the objects. A pick-and-place task for microassembly based on the two TRING-modules can be splitted into several sub-tasks. The

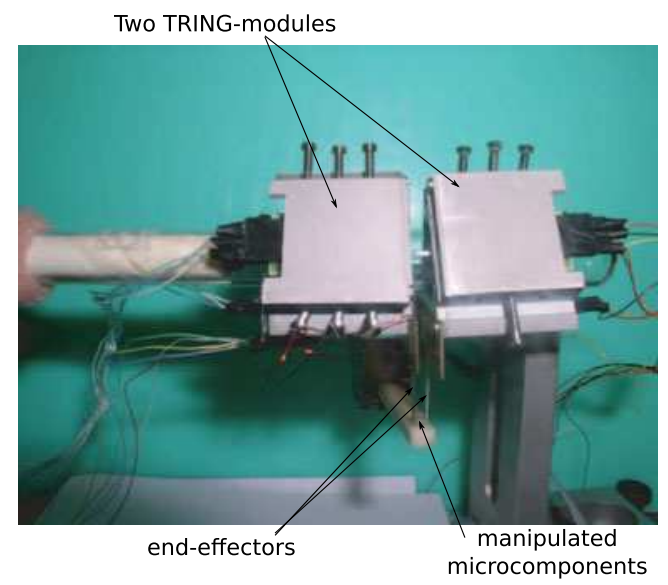

Fig. 10 Two TRING-modules used for pick-and-place tasks in microassembly objective of splitting into sub-tasks is to facilitate the control of the two microrobots. They are as follows.

- Approach: the two microrobots approach near the object to be manipulated. They are both controlled on position in this sub-task.

- Picking: when the microrobots are near the object, one of the two TRING-modules is switched into force control such that its approach is stopped until a given reference force. When this reference force (also called manipulation force) is reached, the picking sub-task is finished.

- Transport: after the picking, the object is transported by the two TRING-modules from its initial location to another location. The microrobot controlled on position has as reference input the final location while the microrobot controlled on force has as reference input the manipulation force.

- Place: when reaching the final location, the force reference given to the microrobot controlled on force is set to zero. The aim is to release slowly the object.

- Moving away: finally, the two microrobots move away from the object in order to completely release the latter. For that, they are controlled on position and their reference inputs correspond to their initial positions.

In Fig. 11a, we present the positions of the two TRINGmodules performing a pick-and-place task, $x_{\mathrm{g}}$ being the position of the left microrobot while $x_{\mathrm{d}}$ that of the right one. All along the task, the left microrobot is controlled on position. On the other hand, the right microrobot is controlled on force between the picking sub-task and the place sub-task.
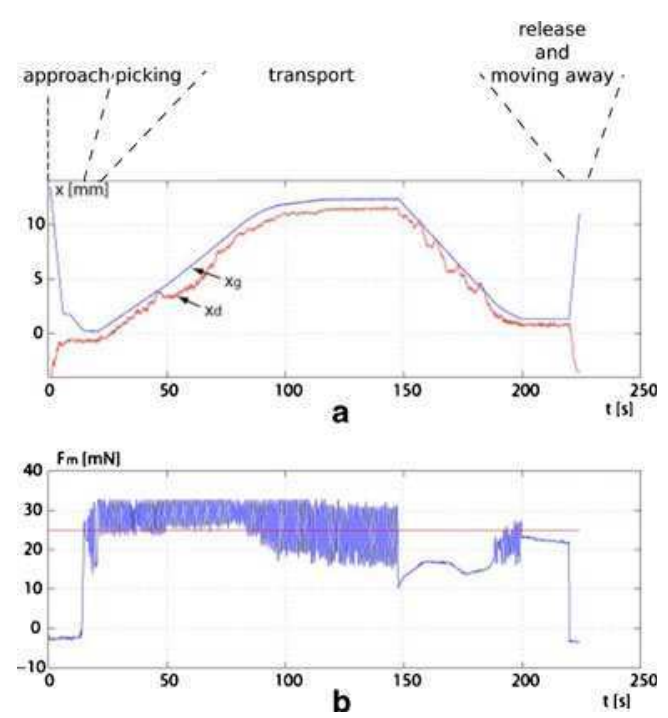

Fig. 11 Evolution of the two TRING-modules performing a pick-andplace task for microassembly 
The different experimental results demonstrated the interesting advantages that bring the TRING-module microrobot in microassembly of small objects. In particular, different sizes of objects can be manipulated, their transport from a location to another one for assembly is large and can be done very precisely, and the manipulation force can be controlled in order to avoid the objects destruction and to obtain a good gripping. Finally, the high dexterity (2 DOF) of the microrobot can also be very benefit for pick-andplace and manipulation in the space, instead of only in the plane.

\subsection{Smart surface}

The manipulation without contact is the best way to manipulate clean or delicate objects such as silicon wafers, glass sheets, solar cell or flat foodstuffs. A new principle of aerodynamic traction using induced air flow is proposed to transport and position objects without contact [17, 35]. The induced air flow surface is a $120 \mathrm{~mm} \times 120 \mathrm{~mm}$ square surface drilled by two kinds of holes (cf. Fig. 12). The object is maintained in constant levitation thanks to the air cushion created by the airflow that comes through a common air inlet. The novelty is that the object can be moved on the table by generating strong vertical air jets through specific holes of the surface. Theses vertical air jets create an induced air flow in the surrounding fluid that pulls the object towards the nozzle (cf. Fig. 12. Each nozzle is driven by an independent solenoid valve. Thus an object can be transported by opening successively the appropriate valves.

The experimental setup for the induced air flow surface is composed of pressurized air supply, two pressure regulators, the set of 56 solenoid valves and its control system, and a computer for vision processing. Figure 13 describes the complete hardware configuration. The induced air flow surface is put on a mechanical platform to adjust its equilibrium position. Default settings for operating pressures are $15 \mathrm{kPa}$ for levitation and $500 \mathrm{kPa}$ for traction. The valves are independently actuated through a multi-channel digital output board (NI USB-6509) and a 5 V/24 V amplifier circuit. A camera is used to grab video frames of the surface of the manipulator. The image processing is done by a computer at the rate of 60 frames per second (the software is cvLink).

\subsubsection{DOF position control}

A control architecture based on two PID controllers is proposed (see Fig. 14). One PID controls the x-position of the object and the other one controls its y-position. The controllers give respectively the number of $y$-directed and $\mathrm{x}$-directed lines of air jets to enable and their position(s) relative to the object.

The PID controllers are tuned with the same coefficients, as the distance between two nozzles along the two directions is the same $(16 \mathrm{~mm})$. The "X pattern" and "Y pattern" blocks calculate the distribution map of the 56 traction nozzles on the surface. They give the position of the nozzles to open depending on the number of y-oriented lines and $\mathrm{x}$-oriented lines to enable and the position of the object. The OR block combines the two patterns using the logical or operator in order to send a unique pattern to the system corresponding to the air jets to enable. The proportional, integral and derivative coefficients of both PID controllers are respectively: $K P=2, K I=0.15$ and $K D=$ 1 . They have been tuned by trial-and-error in previous work [17].

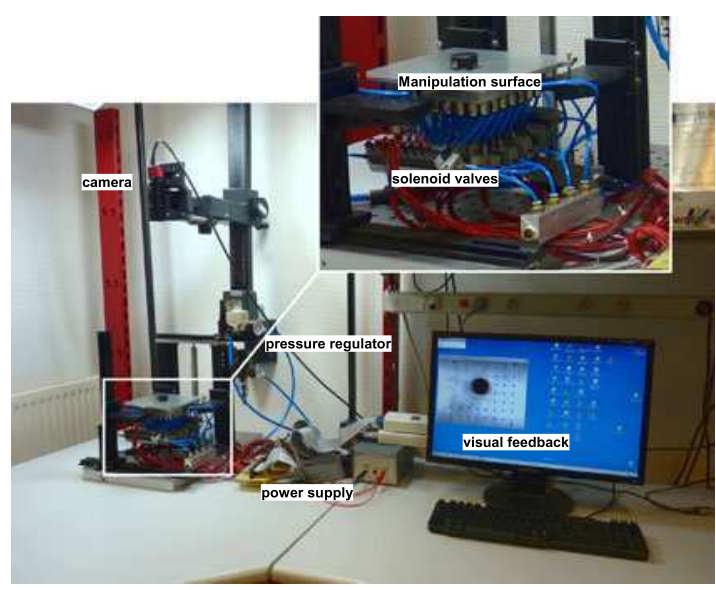

Fig. 13 Overview of the experimental setup
Fig. 12 The induced air flow surface

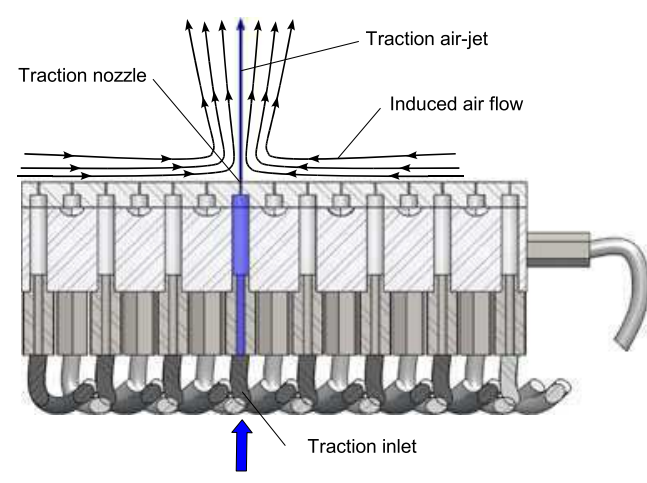




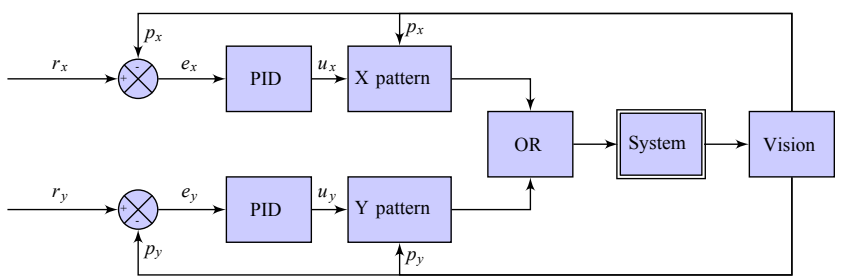

Fig. 14 Control architecture

\subsubsection{Experimental results}

Results are shown in Fig. 15. The measured position of the object is compared to the simulated one. The experimental settling time is about $1.5 \mathrm{~s}$. Small overshoot (less than $5 \%$ ) appears sometimes because of the discretization of the control signal and the minimal distance of $8 \mathrm{~mm}$ between the edge of the object and the nearest sink. The final position of the object varies in a maximal range of $100 \mu \mathrm{m}$. We have also experienced tracking: results are shown in Fig. 16. The performances are quite good, but we can note a tracking error of less than $2 \mathrm{~mm}$ for a speed motion value of $5.03 \mathrm{~mm} / \mathrm{s}$. Performances in tracking could be improved adapting the controller to this aim. The PID controllers robustness has been evaluated using other objects: the system is stable and gives good performances for different objects.

\subsection{Conclusion and future works on the smart surface}

The described new contactless transport system for delicate and clean products may be implemented in several industrial production processes, such as semiconductor manufacturing, solar cell production or food industry. The manipulation and object position control have been experimented on the
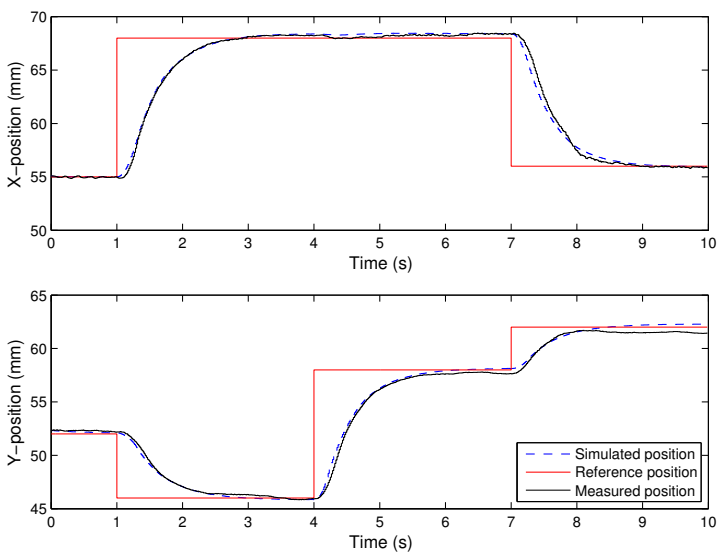

Fig. 15 Experimental results

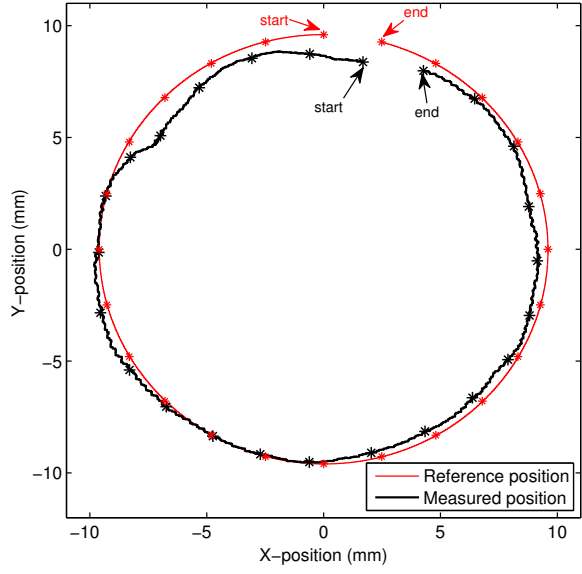

Fig. 16 Target 3D structure at macroscale

device and gives good performances. Robust controllers has been also implemented on the system to guaranty the stability of the closed loop, to deal with the non linearity of the system and with the different shapes of objects [19]. In the future, more complex tasks could be achieved such as 3-DOF positioning, trajectory following, part sorting, etc. We also prospect to miniaturize the device in order to adapt the manipulation principle to millimeter-sized objects (useful in pharmaceutical or watchmaker industries).

\section{3D microassembly using visual servoing}

\subsection{Application}

The application studied is the assembly of five parts by their U-grooves to get stables 3D structures without any use of glue (Fig. 17). The parts and their grooves measure $400 \mu \mathrm{m} \times 400 \mu \mathrm{m} \times 100 \mu \mathrm{m} \pm 1.5 \mu \mathrm{m}$ and $100 \mu \mathrm{m} \times$ $100 \mu \mathrm{m} \times 100 \mu \mathrm{m} \pm 1.5 \mu \mathrm{m}$ respectively leading to an

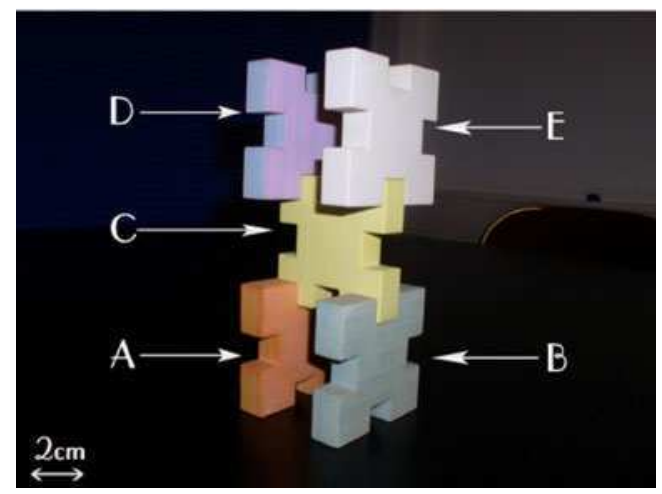

Fig. 17 Target 3D structure at macroscale 
assembly clearance ranging from -3 and $3 \mu \mathrm{m}$. It is a test structure that highlights most of the problems of 3D assembly, notably the need of precision in the control of robot dedicated to the application. This is nothing but the generalization of the assembly of two parts, $\mathbf{A}$ and $\mathbf{B}$ for example. The objective is then to automatically insert a groove of $\mathbf{B}$ into a groove of $\mathbf{A}$ by means of visual servoing. That objective may be divided into three basic tasks that should be performed in the following sequence: positioning of $\mathbf{A}$ at the assembly place (task\#1), positioning of $\mathbf{B}$ at the insertion place (task\#2) and vertical insertion of $\mathbf{B}$ into $\mathbf{A}$ (task\#3) (Fig. 18).

The setup used is positioned inside a controlled environment on a vibration-free table (Fig. 19). It comprises a 5 DOF robotic systems distributed into two robots: a $\mathrm{xy} \alpha$ robot and a $\mathrm{z} \phi$ robot. The former system (positioning table) is equipped with a compliant support and enables positioning of parts in horizontal plane. The latter system (manipulator) supports the gripper and enables vertical positioning and spatial orientation of microparts. The microhandling system is a 2 -finger gripper with 4 DOF (2 per finger) as described in [2]. The imaging system comprises two photon videomicroscopes, but only the one positioned at an angle of $\pi / 4 \mathrm{rad}$ from horizontal plane is used in order to ensure the best perspective view during the assembly tasks. According to the references $[4,22,51,54]$ it can be described by the linear perspective model whose parameters are determined using a 2D calibration rig.

\subsection{Developed solution}

Let $R_{C}, R_{A}, R_{A *_{1}} R_{B}, R_{B *_{1}}$ and $R_{B *_{2}}$ be the frame attached to the camera (i.e. the videomicroscope), the current and final frames of the micropart $\mathbf{A}$, the current, insertion and

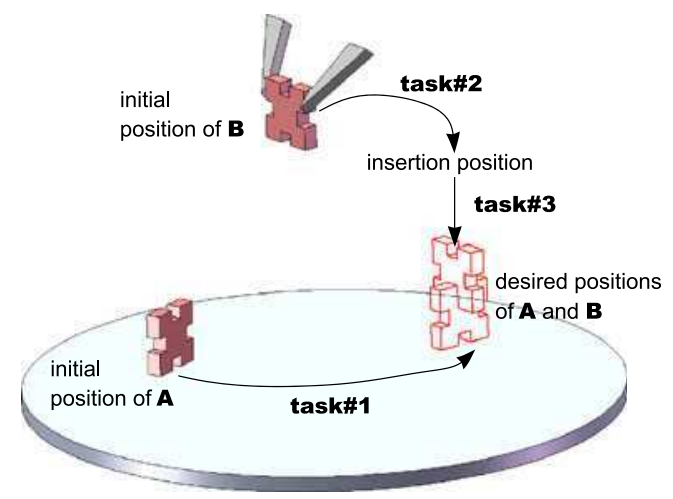

Fig. 18 Objective of the work: insertion of two microparts by their groove

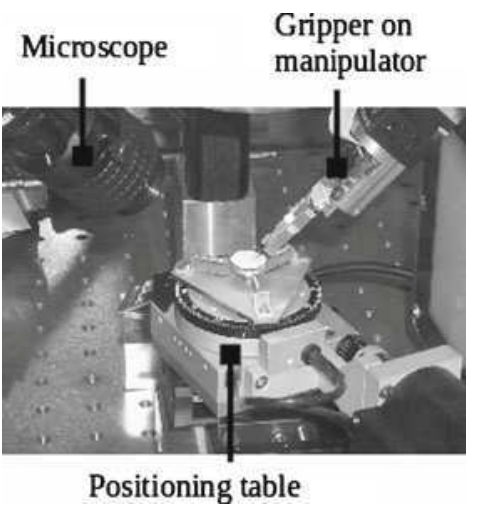

Fig. 19 Assembly setup

final frames of the micropart B, respectively (Fig. 20). A CAD model of the microparts based tracking from [10] is used. It provides, for each new image, the following information:

- ${ }^{c} \mathbf{M}_{A}$, the homogeneous transformation between the camera frame and the current position of $\mathbf{A}$,

- ${ }^{c} \mathbf{M}_{B}$, the homogeneous transformation between the camera frame and the current frame of $\mathbf{B}$.

Let

- ${ }^{c} \mathbf{M}_{A *}$ be the homogeneous transformation between the camera frame and the desired frame of $\mathbf{A}$,

- ${ }^{c} \mathbf{M}_{B *_{1}}$ be the homogeneous transformation between the camera frame and the insertion frame of $\mathbf{B}$,

- ${ }^{c} \mathbf{M}_{B *_{2}}$ be the homogeneous transformation between the camera frame and the desired frame of $\mathbf{B}$.

Fig. 20 Diagram of the insertion of part $\mathbf{B}$ into $\mathbf{A}$ 
They are obtained either in tele-operated mode (using a joystick) or directly from the CAD model.

Let $R_{F}$ be the base frame of the workcell. The homogeneous transformation between the camera frame $R_{C}$ and the workcell frame $R_{F}$ is noted ${ }^{F} \mathbf{M}_{A}$ and is computed for each object pose.

For each task the regulation to zero of the error $\mathbf{e}$ defined from ${ }^{i} \mathbf{M} *$ consists of choosing $S=\left({ }^{F} t_{i}, \theta u\right)$ as the current 3D pose and $s *=\left(F_{t *}, 0\right)$ as the desired pose of the micropart $i$, respectively:

$\mathbf{e}=F_{t_{i}}-{ }^{F} t_{i *} \theta u$

The corresponding control law defined by the exponential decrease of the error is then:

$$
\begin{aligned}
v_{F}^{\omega_{F}} & =-\lambda \begin{array}{ll}
\mathbf{I}_{3 \times 3} & \mathbf{0}_{3 \times 3} \\
\mathbf{0}_{3 \times 3} & \mathbf{J}_{\omega}^{-1}
\end{array} \quad(s-s *) \\
& =-\lambda \begin{array}{l}
{ }^{F} t_{i}-{ }^{F} t_{i *} \\
{ }^{F} \mathbf{R}_{i} \theta u
\end{array}
\end{aligned}
$$

The task 1 involves the control of the $\mathrm{xy} \alpha$ table as:

$$
\begin{aligned}
& \left(\begin{array}{c}
v_{x} \\
v_{y}
\end{array}\right)=-\lambda_{1}\left(\begin{array}{ll}
F^{F} t_{x}-F & t_{x *} \\
t_{y}-F & t_{y *}
\end{array}\right) \\
& \omega_{\alpha}{ }_{F} \quad{ }^{F} \mathbf{R}_{A} \theta u_{\alpha}
\end{aligned}
$$

The task 2 involves the control of the $\mathrm{xy} \alpha$ table as:

$$
\begin{aligned}
& \left(\begin{array}{c}
v_{x} \\
v_{y}
\end{array}\right)=-\lambda_{2}\left(\begin{array}{ll}
F t_{x}-F & t_{x *} \\
F_{t_{y}}-F & t_{y *}
\end{array}\right) \\
& \omega_{\alpha}{ }_{F} \quad F_{\mathbf{R}_{B}} \theta u_{\alpha}
\end{aligned}
$$

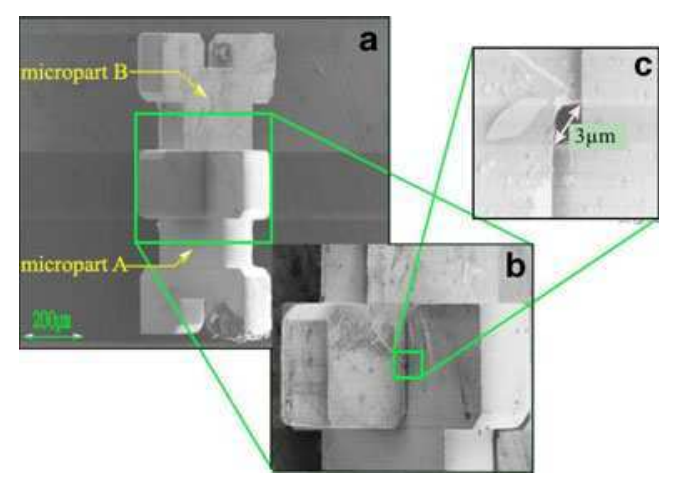

Fig. 21 Some images of the assembled structure from a scanning electron microscope

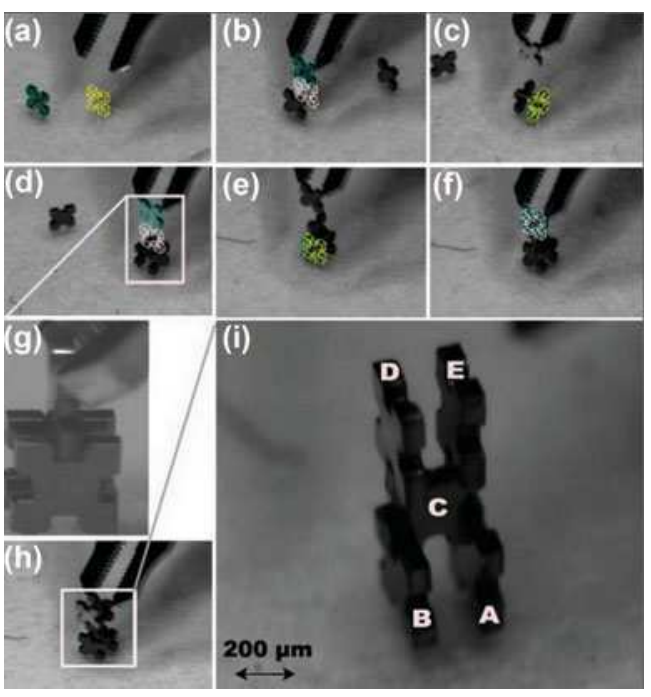

Fig. 22 Assembly of five parts on three levels

The task 3 involves the control of the $\mathrm{z} \phi$ manipulator as:

$$
\begin{array}{ll}
v_{z}=-\lambda_{3} & { }^{F} t_{z}-{ }^{F} t_{z *} \\
\omega_{\phi} & { }^{F} \mathbf{R}_{A} \theta u_{\phi}
\end{array}
$$

The terms $\lambda, \lambda_{1}, \lambda_{2}$ and $\lambda_{3}$ are the gains enabling the modulation of the decrease speed.

\subsection{Results and discussions}

Figure 21 shows some SEM (scanning electron microscope) images of the final assembly. The obtained mechanical play is about $3 \mu \mathrm{m}$ showing the relevance of the tracking to deliver high quality pose measurement compatible with microassembly. The final positioning and orientation errors are $3.5 \mu \mathrm{m}$ and $0.3 \times 10^{-2} \mathrm{rad}$, respectively.

The approach works despite partial occlusions of parts and blurred images (because of the small depth of field of the microscope).

The assembly is performed successively 10 times, it takes an average of $41 \mathrm{~s}$ with a standard deviation of $3 \mathrm{~s}$.

Figure 22 shows some images of the final assembly of five parts and some steps: a right and stable structure is obtained without any use of solidaring effect.

\section{Microassembly of MOEMS using force control}

\subsection{Force guided micro-assembly tasks based on active gripping}

Using force control to achieve micro-assembly processes is a relevant but complex approach. On the one hand, force 


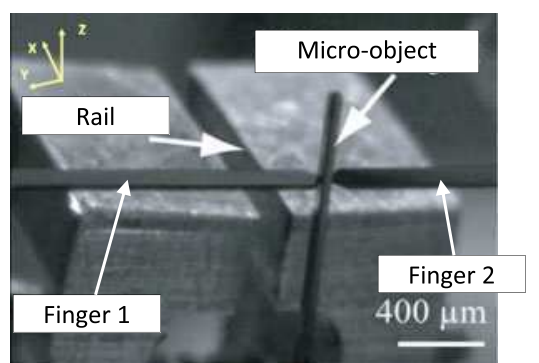

Fig. 23 Guiding task: a micro-object is held between two fingers of a microgripper and guided in the rail

sensing brings high dexterity which is all the more important at the micro scale than macro one: Indeed micro scale assembling suffers from surface force predominance, difficulties of other sensing alternatives (vision are huge sensors for example) but also lack of knowledge. On the second hand, force sensors have to be very small to be closely integrated to the contacts (handled micro-object and fingers of the microgripper for example) to ensure good quality of measurement and to measure forces of some hundreds of Micro-Newtons. Very few technologies are today available to enable such sensors development.

Based on those statements, two force sensors from femtotools (Switzerland) were integrated to form a microgripper (Fig. 23). This microgripper thus provides the measured contact force between finger 1 and the components but also between finger 2 and the same component. Such a microgripper can be used to perform automated cycles including pick, motions and place tasks. Figure 23 displays the experimental set-up used to perform a guiding task (guiding of the micro-object along a rail). During such a task, contacts between the micro-object and the rail happen when moving the microgripper along the rail axis $(\mathrm{X})$. Contact forces can be estimated through force sensors and a behavioral model of the whole microgripper (force sensors, microobject subjected to a lateral (Y) force) [43]. Based on these estimations, the force control along $\mathrm{Y}$ is ensured [41]. Figure 24 displays the forces and positions during such a guiding task. Based on this principle, automated guiding tasks based on force control were ensured for the first time with good stability and robustness [40, 41].

\subsection{Assembled micro-optical benches}

Micro-assembly enables to combine in the plane or out of plane several chips issued from different and incompatible microfabrication processes. This approach is particularly interesting in the field of MOEMS because it enables to combine basic optical components issued from dedicated microfabrication processes and then conducts to a product with good optical properties.

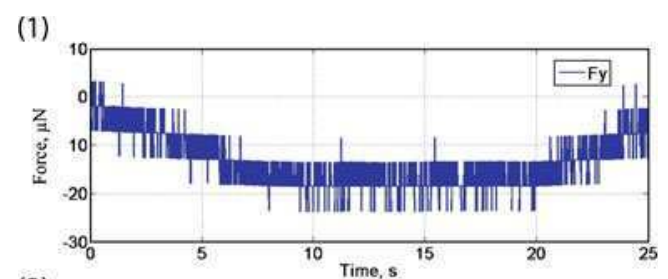

(2)

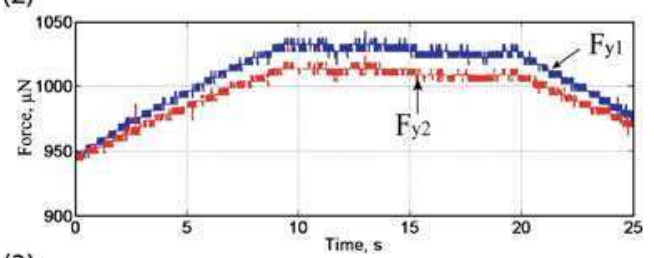

(3)

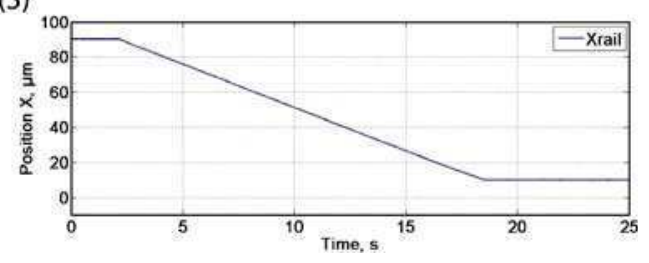

Fig. 24 Forces acting during a guiding task: (2) measured contact forces between micro-object and fingers 1 and $2(1)$ is the estimated contact force between micro-object and rail and (3) is the positioning of the micro-object along the rail

In the present case, active (based on piezoelectric material) microgripping is used which is an extremely interesting approach because it enables to adapt the relative position of two components during the assembly process (through accurate control) but also to ensure high contact forces in a reversible way. A micro-assembly station has been developed (Fig. 25) to ensure the assembly of RFS-MOB (Reconfigurable Free Space Micro-Optical Bench). RFSMOB is composed of a set of several kinds of Silicon components that have been designed to be easily and accurately

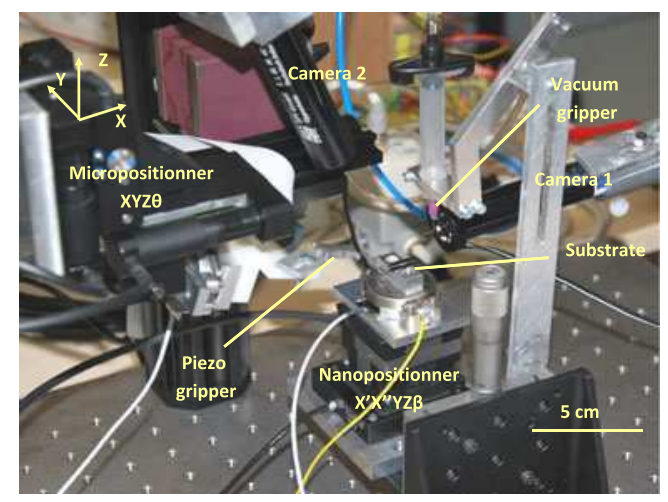

Fig. 25 Micro-assembly cell comprising one 4 DOF piezoelectric microgripper, two robotized arms split onto 9 DOF (micropositionner and nanopositionner), one vacuum gripper and two high magnification cameras 


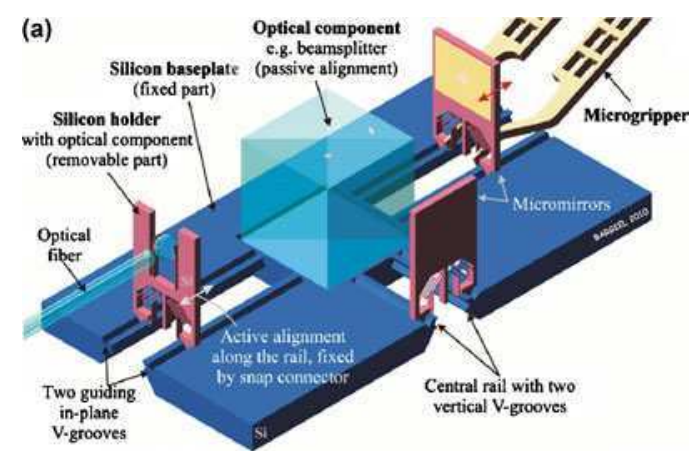

(b)

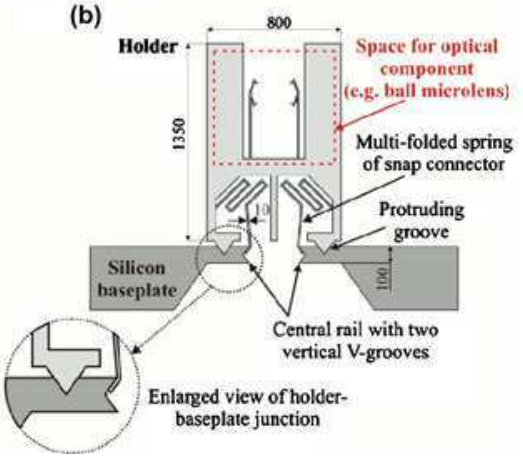

Fig. 26 Assembled RFS-MOB: b Every holder possesses one optical functionality and is assembled onto a substrate. Its positioning accuracy is ensured thanks to a V-groove system whereas its holding is done by springs. a Such elementary assemblies can be combined onto the substrate to achieve various and complex optical functionalities

manipulated and assembled onto a baseplate [5] (Fig. 26). Each holder possesses one optical property (some are micromirrors, others have ball lens or beam splitter for example). Assembly of each holder onto the substrate is done using an active (piezo driven) microgripper. Figure 27 Displays one example of assembled RFS-MOB comprising 3 holders assembled onto a substrate [42].

\subsection{Positioning accuracy achieved}

Previous sections shown that complex micro-assemblies can be performed. Nevertheless, obtaining good and suitable

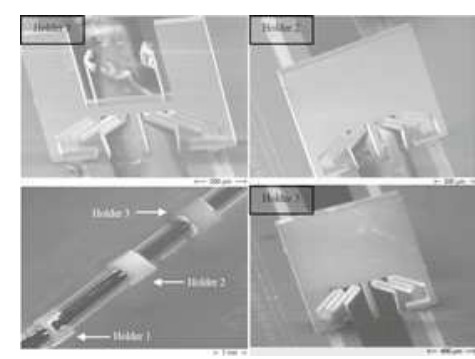

Fig. 27 Assembled RFS-MOB composed of three holders all being aligned along one optical path

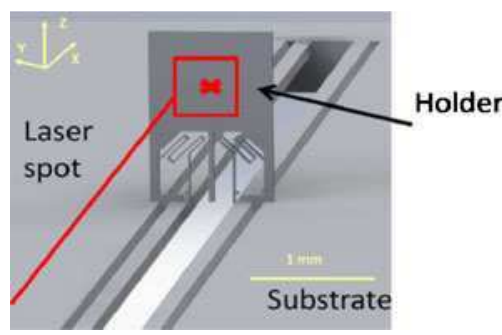

Fig. 28 Laser based scanning of a holder to characterize its positioning accuracy relative to the substrate

positioning accuracy is at the same time a very important challenge and requires information from an optical performances point of view. To ensure the best positioning accuracy, a specific V-Groove design has been proposed. Each holder has two male V-grooves perfectly fitting with female V-rails fabricated into the baseplate (Fig. 26b). A system based on small springs then enables to hold the holder onto the baseplate once micro-assembly performed.

To characterize the positioning accuracy of one holder relative to its substrate, a laser based scanning is performed after micro-assembling (Fig. 28) [42]. The gripping principle used being based on active gripping, it is then possible to adapt the position of the holder to improve its positioning accuracy. Several sets of micro-assembling processes were performed [6]. During each set, ten different positioning were performed and shown that a positioning accuracy better than the micron (along $X$ ) and better than $0.1^{\circ}$ around $\mathrm{Y}$ and $\mathrm{Z}$ can be ensured.

\section{Teleoperated assembly of 40 microns objects}

The last category of works deals with smaller object whose size is between 10 to 100 microns. At that scale adhesion cannot be neglected and should be taken into account in the design of handling strategies. We are proposing a new reliable and reversible method to position micro-object on a substrate. The principle is an hybrid strategy between adhesion manipulation and gripping. It is based on a hierarchy of forces. In one hand, to guarantee object's release, the adhesion force between object and substrate must be higher than the adhesion force between object and gripper along the normal vector $\mathbf{n}$ of the substrate (see in Fig. 29a):

$F_{\text {object-substrate }}^{\text {adhesion }} \quad F_{\text {object-gripper }}^{\text {adhesion }}$

To reduce the impact of external perturbations, $F_{\text {object-gripper }}^{\text {adherion }}$ must be lower as possible and $F_{\text {object-substrate }}^{\text {adhes }}$ must be higher as possible. The major drawback of this release method is the difficulties to grasp the object on the substrate [28]. A 


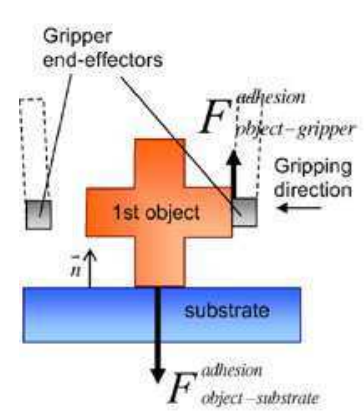

(a) Releasing the first object on the substrate

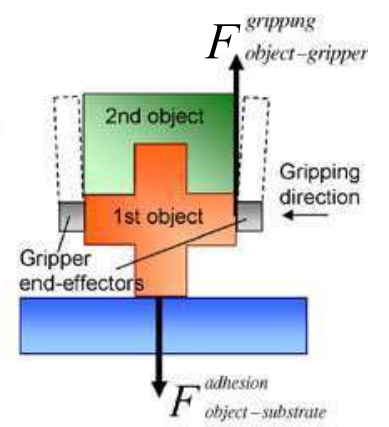

(b) Grasping the first object from the substrate

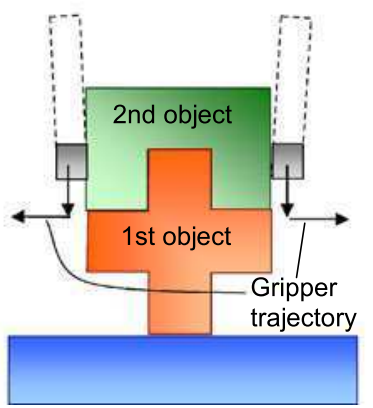

(c) Releasing the second object

Fig. 29 Principle of the Release and Grasping of the objects

reliable grasping cannot be obtained by using only the adhesion force of the gripper. This method is a good way to release the object but not for grasping.

In other hand, to grasp the object, a gripping force higher than the adhesion force between substrate and object along the direction $\mathbf{n}$ is required (see in Fig. 29b):

$F_{\text {object-gripper }}^{\text {gripping }} \quad F_{\text {object-substrate }}^{\text {adhesion }}$

One of the best technological solution is to use gripper with two fingers where the gripping force could be easily higher than adhesion between the object and the substrate.

Our hybrid method uses advantages of both adhesion manipulation and gripping. It induces a reliable release and grasping of micro-object. To guarantee, the conditions (6) and (7), the gripper must have a high ratio between its gripping force and the adhesion force 'object-gripper'.

As presented in Fig. 29, two ways have been chosen to guarantee first object's manipulation: increase adhesion forces between the substrate and the object and decrease adhesion force between the object and the gripper.

We choose to use as substrate a transparent gel film wellknown in microelectronics: Gel-Pak. This material is in fact transparent and softly adhesive, it consequently allows accurate pick and place tasks. Moreover, the low mechanical stiffness of this polymer induces natural compliance of the substrate required for micro-assembly. In a second time,

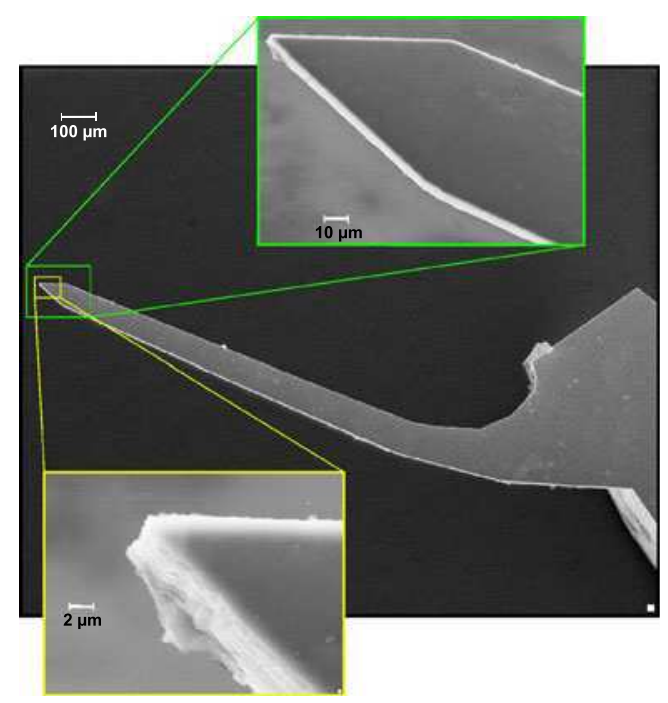

Fig. 30 End-effectors' shape in SEM view. Scalloping is visible in lower picture

efforts have been made on end-effectors shaping. First, surface in contact with the micro-object has been reduced by using end-effectors with a small thickness. In second time, the fabrication process called DRIE have been used to give the gripping surface a specific texture. Etching anisotropy of this process is made by a short succession of isotropic etching/protection cycles. These cycles create a phenomenon called scalloping illustrated in Fig. 30. In this way, contact shape between object and end-effectors is a succession of microscopic contact points. The roughness induced by DRIE is able to highly reduce pull-off force. As presented in Fig. 31, nanostructurations or chemical functionalisations can also be used to reduce the adhesion on the gripper end-effectors [13-16].

\subsection{Experimental set-up}

The experimental set-up is based on the piezoelectric gripper presented above. Several kind of finger tips can be glued

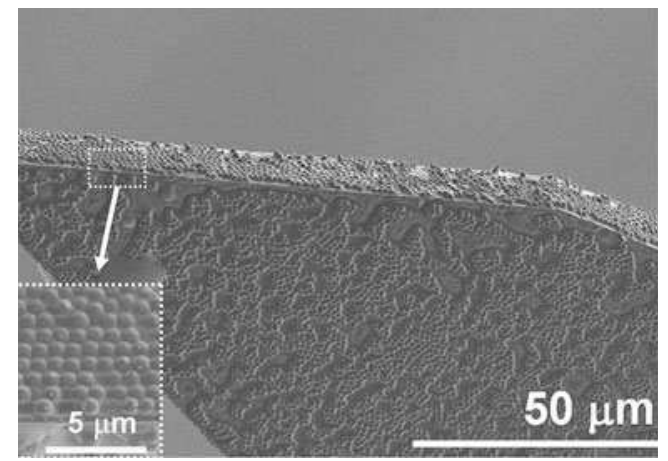

Fig. 31 Nanostructuration of end-effectors' shape (collaborative works between FEMTO-ST and EMPA Institute, Thun, Switzerland) [16] 
on this piezoelectric actuator. The finger tips $[3,29]$ used for micro-assembly have been designed to handle microscopic objects. They are build in single crystal silicon SOI wafer by a well-known microfabrication process: DRIE. These endeffectors have a long and thin beam $(12 \mu \mathrm{m})$ designed to handle objects from $5 \mu \mathrm{m}$ to few hundred micrometers.

Testing micro-assembly needs micro-objects that could be mechanically fastened to the others. Thus, micro-objects have been designed with mechanical fastener structures already studied in [12]. To supply a challenging benchmark, objects' shape are squares of $40 \mu \mathrm{m}$ sides with a thickness of $5 \mu \mathrm{m}$. SOI wafers of $5 \mu \mathrm{m}$ device layer thickness and DRIE process have been used to build these microparts [30]. Many shapes, fastener designs and sizes were tested (Fig. 32). Two kind of parts are presented in this article: the first one is $40 \mu \mathrm{m}$ square puzzle parts, with four notches of $5 \mu \mathrm{m}$. The second one is a mechanical plug device between two $40 \mu \mathrm{m}$ squares. The male part have a key which is able to lock the female part after assembly as proposed by Dechev [12].

\subsection{Results}

This approach has been tested in teleoperate mode to assemble benchmark micro-objects. Two kind of mechanical assembly have been tried to make a three-dimensional microproduct. The first one is made by an insertion of two identical puzzle parts. The second one is a reversible assembly of two different parts.

\subsubsection{Insertion}

Each puzzle piece has four notches, close to $5 \mu \mathrm{m}$ width and $10 \mu \mathrm{m}$ long. As part's thickness is $5 \mu \mathrm{m}$, assembly of two pieces requires to insert perpendicularly (Fig. 33).

The first part is gripped and place vertically on the substrate. The second part is taken vertically too perpendicularly to the first one (step 1). Then two puzzle pieces are ready to be assembled. Then the second part is gripped,

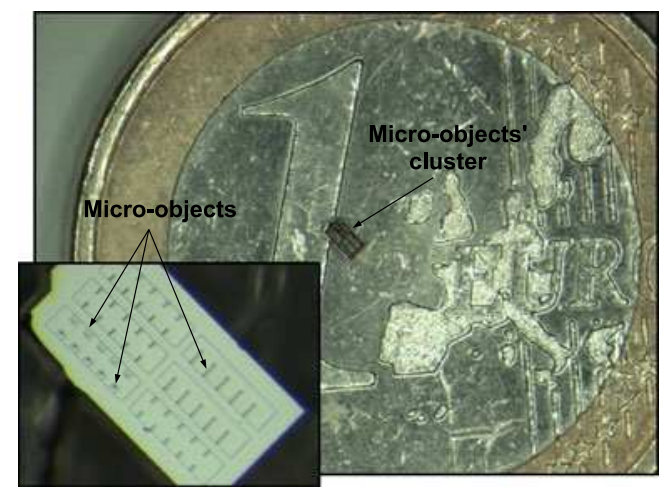

Fig. 32 Micro-objects designed for assembly
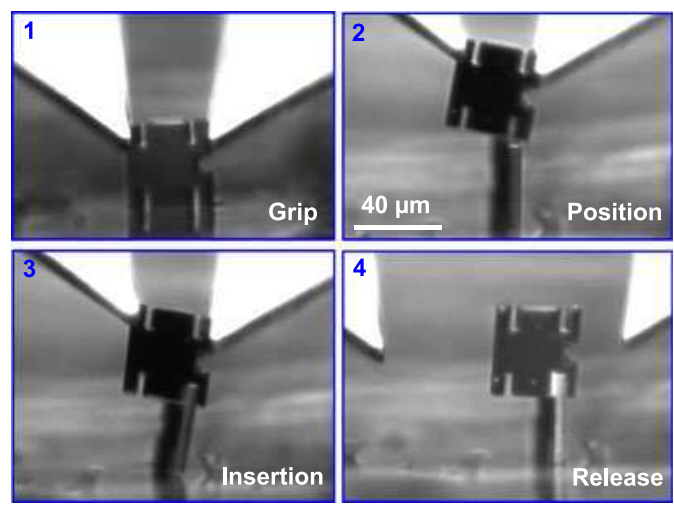

Fig. 33 Insertion assembly

and is accurately positioned above the first part (step 2). Assembly clearance is very small and evaluated to $200 \mathrm{~nm}$ by SEM measurement and accuracy can be made up by substrate compliance. Indeed, compliance of adhesive substrate allows small rotative motion of the first part thus insertion is easily performed without any fine orientation of the gripper (step 3). When insertion is complete, microgripper is opened to release assembled part (step 4). This last operation can failed when adhesive effects between gripper and puzzle piece are stronger than between both puzzle pieces. In fact, the part stay sticked on the end-effector and opening the gripper disassemble the micro-product. Consequently, the trajectory proposed in Fig. 33 is used to induce a reliable release.

\subsubsection{Reversible assembly}

The second assembly benchmark requires more steps and more accuracy. Both mechanical parts are different but have the same square shape of $40 \mu \mathrm{m}$ side. The first part have a small key joint with a $\mathrm{T}$ shape on one side. The second part have a $\mathrm{T}$ shaped imprint in center of the square (Fig. 34). To perform assembly, the key must be inserted in the imprint and then a lateral motion of the second part locks the assembly. This benchmark is inspired from Dechev et al. [12].

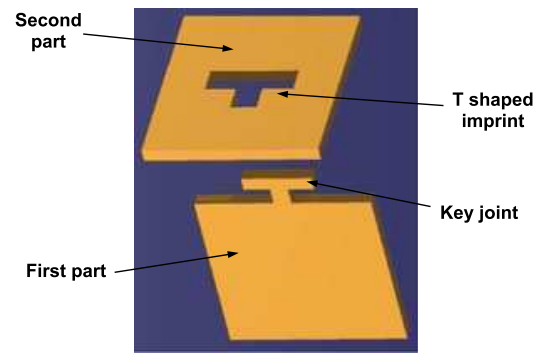

Fig. 34 Lock joint design 
This benchmark has been tested with our robotic structure (Fig. 35). Parts' orientation is very important, especially for the relative orientation between both micro-objects. The first part is set vertically on the substrate. The gripper is used to grip and align the second part above the key (step 1). When the key is in the imprint (visible on the vertical view), a vertical motion puts the key in the hole (step 2). Finally a lateral motion locks the key and the assembly is performed (step 3).

After locking motion, the 3D microproduct realized can be extracted from the substrate and moved to another place (step 4). Moreover the major interest of this kind of assembly is the possibility to disassemble it. To perform it, motions are repeated on opposite way: a lateral motion to unlock the key (step 5) and a vertical motion to disengage the key from the imprint (step 6). Several cycles of assembly-disassembly have been tested.

\subsubsection{Analysis of the reliability}

In order to show the reliability of our method, numerous pick and place operations have been performed in teleoperation and in an automatic cycle. The tests have been done on a silicon micro-objects whose dimensions are $5 \times 10 \times 20 \mu^{3}$. The objective of the pick and place operation is to grasp the object placed on the substrate, to move it along $100 \mu \mathrm{m}$ and to release it on the substrate. To evaluate the reliability, the success rate of the pick and place operations and the time cycle have been measured.

First, tests have been done in teleoperation. The operator see the lateral view and the vertical view on two screens. He controls the trajectories and the gripper movements with a joystick without force feedback. Sixty operations have been done. The time cycle stays always between 3 and $4 \mathrm{~s}$. Secondly, tests have been done in an automatic cycle without force and position feedback. The pick and place trajectory was repeated 60 times and the time cycle was $1.8 \mathrm{~s}$.

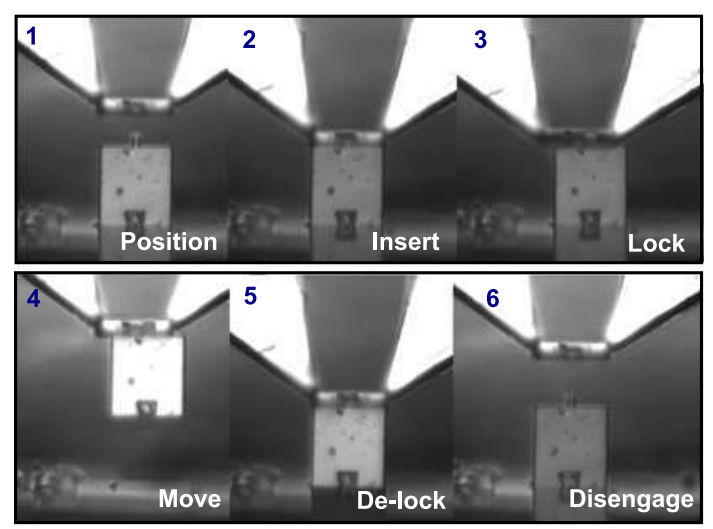

Fig. 35 Reversible assembly
In both tests, the reliability reaches $100 \%$. As only some articles in the literature quote the reliability of micromanipulation methods, it is quite difficult to compare this value with other works. However, tests of the reliability of microhandling strategies have been presented in [11, 24]. Both tests have been done on polystyrene spheres whose diameter is $50 \mu \mathrm{m}$. The success rate was between 51 and $67 \%$ on around 100 tests in [24] and was between 74 and $95 \%$ on 60 tests in [11]. Consequently, our method allows a higher reliability on smaller objects which represents a significant contribution.

\section{Conclusion}

This paper has drawn an overview of the scientific works of FEMTO-ST institute in the automation of 'microassembly' and 'micromanipulation' based on robotic means. We gave three major proposals for microrobotics means which have been developed during the last decade: a piezoelectric microgripper that can move finely grasped objects in two directions and rotation (an industrial version of this microgripper is now on the market), a 2 DOF modules, named TRING-module that can move objet on a long coarse in translation and rotation, and the smart surface we currently studied. The paper proposed several method for the automation of out of plane assembly of objects whose typical size is from 10 to 400 microns. Closed loop control based on micro-vision has been studied and applied on the fully automatic assembly of several 400 microns objects. Force control has been also analyzed and is used for optical Microsystems assembly. At least, open loop trajectories of 40 microns objects with a throughput of 1,800 unit per hour have been achieved. Scientific and technological aspects and industrial relevance have been presented. The research group is now continuing its work on the assembly and manipulation of components and processes of smaller objects. We focus on challenges of assembling components of less than $10 \mu \mathrm{m}$ up to hundreds of nanometers. For this, we develop new strategies to manipulate, new manipulation tools, new methods of control of high precision (integrating the noises for example), integrated microfabricated sensors, ... Micromanipulation and micro-assembly around the micrometer is a key step in the packaging of nanotechnologies and is thus a bottleneck for the advent of nanotechnological products.

Acknowledgments These works have been supported by the French National Agency (ANR) under NANOROL contract ANR-07ROBO-0003: Nanoanalyse for micromanipulate, PRONOMIA Contract ANR No. 05-BLAN-0325-01 and SMART BLOCKS contract ANR-2011-BS03-005, the European Union under EUPASS contract IST-NMP-1-507978-2: Evolvable Ultra Precision Assembly Systems: Next Generation Technologies for Rapid Deployment of Distributed Ultra Precision Assembly Services for Manufacture of Micro- and 
Nano-scale Products, HYDROMEL contract NMP2-CT-2006-026622: Hybrid ultra precision manufacturing process based on positionaland self-assembly for complex micro-products, FAB2ASM contract FoF.NMP.2012-3: Efficient and Precise 3D Integration of Heterogeneous Microsystems from Fabrication to Assembly, and by the Franche-Comté region under the MIAAMI and MIOP Projects and NEMO/Marie-Curie. Authors would like to thank C. Gorecki and S. Bargiel, from the MN2S Department of FEMTO-ST for their contribution on MOEMS assembly.

\section{References}

1. Abadie J, Piat E, Oster S, Boukallel M (2012) Modeling and experimentation of a passive low frequency nanoforce sensor based on diamagnetic levitation. Sens Actuators, A, Phys 173:227-237

2. Agnus J, Nectoux P, Chaillet N (2005) Overview of microgrippers and design of a micromanipulation station based on MMOC microgripper. In: IEEE international symposium on computational intelligence in robotics and automation. CIRA, Finland

3. Agnus J, Hériban D, Pétrini V, Gauthier M (2009) Silicon end-effectors for microgripping task. J Precis Eng. doi:10.1016/j.precisioneng.2009.02.005

4. Ammi M, Ferreira A (2004) Haptically generated paths of an AFM-based nanomanipulator using potential fields. In: Proceedings of the 2004 IEEE nano. Munich, Germany

5. Bargiel S, Rabenorosoa K, Clévy C, Gorecki C, Lutz P (2010) Towards micro-assembly of hybrid MOEMS components on a reconfigurable silicon free-space micro-optical bench. J Micromechanics Microengineering (JMM) 20. doi:10.1088/0960-1317/20/4/045012

6. Bargiel S, Rabenorosoa K, Mascarob JP, Clévy C, Gorecki C, Lutz P (2010) Technology platform for hybrid integration of MOEMS on reconfigurable silicon micro-optical table. In: Eurosensors XXIV. Linz, Austria

7. Bergander A, Driesen W, Varidel T, Breguet J (2003) Monolithic piezoelectric push-pull actuators for inertial drives. In: IEEE international symposium micromechatronics and human science, pp 309-316

8. Boudaoud M, Haddab Y, Gorrec YL (2012) Modeling and optimal force control of a nonlinear electrostatic microgripper. IEEE/ASME Trans Mechatron 18(3):1130-1139

9. Chen Q, Haddab Y, Lutz P (2011) Microfabricated bistable module for digital microrobotics. J Micro-Nano Mechatron 6(1-2): $1-12$

10. Comport AI, Marchand E, Pressigout M, Chaumette F (2006) Real-time markerless tracking for augmented reality: the virtual visual servoing framework. IEEE Trans Vis Comput Graph 12(4):615-628

11. Dafflon M, Lorent B, Clavel R (2006) A micromanipulation setup for comparative tests of microgrippers. In: International symposium on robotics (ISR)

12. Dechev N, Mills JK, Cleghorn WL (2004) Mechanical fastener designs for use in the microassembly of $3 \mathrm{~d}$ microstructures. In: Proceedings of ASME IMECE 2004

13. Dejeu J, Gauthier M, Rougeot P, Boireau W (2009) Adhesion forces controlled by chemical self-assembly and $\mathrm{PH}$, application to robotic microhandling. ACS Appl Mater Interf 1(9):1966-1973

14. Dejeu J, Rougeot P, Gauthier M, Boireau W (2009) Reduction of micro-object's using chemical functionalisation. Micronanoletters 4(2):74-79

15. Dejeu J, Rougeot P, Gauthier M, Boireau W (2009) Robotic microhandling controlled by chemical self-assembly. In: Proc. of the IEEE/RSJ int. conf. on robotics and intelligent systems. St. Louis, Missouri, USA

16. Dejeu J, Benchelany M, Philippe L, Rougeot P, Michler J, Gauthier M (2010) Reducing the adhesion between surfaces using surface structuring with PS latex particle. ACS Appl Mater Interf 2(6):1630-1636

17. Delettre A, Laurent G, LeFort-Piat N (2010) 2-DOF contactless distributed manipulation using superposition of induced air flows. In: IROS2010-IEEE international conference on intelligent robots and systems, pp 2351-2356

18. Delettre A, Laurent GJ, Haddab Y, Fort-Piat NL (2012) Robust control of a planar manipulator for flexible and contactless handling. IFAC Int J Mechatron 22(6):852-861

19. Delettre A, Laurent GJ, Haddab Y, Fort-Piat NL (2012) Robust control of a planar manipulator for flexible and contactless handling. Mechatronics. doi:10.1016/j.mechatronics.2012.05.003

20. Dembele S, Bert J, Tamadazte B, Lefort-Piat N (2010) A trifocal transfer based virtual microscope for robotic manipulation of MEMS components. J Optomechatron 4(4):342-361

21. Dong W, Rostoucher D, Gauthier M (2010) A novel integrated micro-force measurement system for plane-plane contact research. Rev Sci Instrum 81:116101. doi:10.1063/1.3488382

22. Figl M, Ede C, Hummel J, Wanschitz F, Ewers R, Bergmann H, Birkfellner W (2005) A fully automated calibration method for an optical see-through head-mounted operating microscope with variable zoom and focus. IEEE Trans Med Imag 24(11):14921499

23. Gauthier M, Nourine M (2007) Capillary force disturbances on a partially submerged cylindrical micromanipulator. IEEE Trans Robot 23(3):600-604

24. Gauthier M, Lopez-Walle B, Clévy C (2005) Comparison between micro-objects manipulations in dry and liquid mediums. In: Proc. of CIRA'05

25. Gauthier M, Régnier S, Rougeot P, Chaillet N (2006) Forces analysis for micromanipulations in dry and liquid media. $\mathrm{J}$ Micromechatron 3(3-4):389-413

26. Gauthier JY, Hubert A, Abadie J, Chaillet N, Lexcellent C (2007) Original hybrid control for robotic structures using magnetic shape memory alloys actuators. In: IEEE IROS. San Diego, CA, pp 747752

27. Grossard M, Boukallel M, Chaillet N, Rotinat-Libersa C (2011) Modeling and robust control strategy for a control-optimized piezoelectric microgripper. IEEE/ASME Trans Mechatron (TMech) 16(4):674-683

28. Haliyo D, Régnier S (2002) Manipulation of micro-objects using adhesion forces and dynamical effects. In: Proceedings of ICRA/IEEE international conference on robotics and automation

29. Heriban D, Agnus J, Coudevylle JR, Gauthier M, Chaillet N (2005) Design of silicon finger tips for a MOC (microrobot on chip) microgripper. In: Proc. of the int. workshop on topica meeting on microfactories (TMMF05). Tsukuba, Japan

30. Hériban D, Agnus J, Pétrini V, Gauthier M (2009) Mechanical detethering technique for silicon MEMS etched with dried process. J Micromechanics Microengineering 19(5):055,011

31. Ivan I, Rakotondrabe M, Lutz P, Chaillet N (2009) Current integration force and displacement self-sensing method for cantilevered piezoelectric actuators. Rev Sci Instrum (RSI) 80(12):2126,103

32. Ivan I, Rakotondrabe M, Lutz P, Chaillet N (2009) Quasi-static displacement self-sensing method for cantilevered piezoelectric actuators. Rev Sci Instrum (RSI) 80(12):065,102

33. Khadraoui S, Rakotondrabe M, Lutz P (2012) Interval modeling and robust control of piezoelectric microactuators. IEEE Trans Control Syst Technol (T-CST) 20(2):486-494 
34. Kharboutly M, Gauthier M, Chaillet N (2010) Predictive control of a micro bead's trajectory in a dielectrophoresis-based device. In: IEEE IROS

35. Laurent G, Delettre A, Fort-Piat NL (2011) A new aerodynamic traction principle for handling products on an air cushion. IEEE Trans Robot 29(2):379-384

36. Lit PD, Agnus J, Chaillet N (2003) The constitutive equations of a piezoelectric duo-bimorph. In: IEEE international symposium on assembly and task planning, pp 1-6

37. Lit PD, Agnus J, Clévy C, Chaillet N (2004) A four-degree-offreedom microprehensile microrobot on chip. J Assem Autom 24(1):33-42

38. Lopez-Walle B, Gauthier M, Chaillet N (2008) Principle of a submerged freeze gripper for micro-assembly. IEEE Trans Robot 24(4):897-902

39. Rabenorosoa K, Clévy C, Lutz P, Gauthier M, Rougeot P (2009) Measurement of pull-off force for planar contact at the microscale. Micro Nano Lett 4:148-154

40. Rabenorosoa K, Clévy C, Lutz P (2010) Hybrid force/position control applied to automated guiding tasks at the microscale. In: IEEE/RSJ international conference on intelligent robots and systems (IROS)

41. Rabenorosoa K, Clévy C, Lutz P (2010) Active force control for robotic micro-assembly: application to guiding tasks. In: IEEE ICRA, international conference on robotics and automation

42. Rabenorosoa K, Clévy C, Bargiel S, Mascaro JP, Lutz P, Gorecki C (2011) Modular and reconfigurable 3d micro-optical benches: concept, validation, and characterization. In: International manufacturing science \& engineering conference

43. Rabenorosoa K, Clévy C, Chen Q, Lutz P (2012) Study of forces during micro-assembly tasks using two-sensingfinger grippers. IEEE/ASME Trans Mechatron. 10.1109/TMECH. 2011.2131673

44. Rakotondrabe M, Gorrec YL (2010) Force control in piezoelectric microactuators using self scheduled HINF technique. In: IFACMech (Symposium on mechatronic systems). Cambridge, MA, USA, pp 417-422
45. Rakotondrabe M, Haddab Y, Lutz P (2008) Voltage/frequency proportional control of stick-slip microsystems. IEEE Trans Control Syst Technol (T-CST) 16(6):1316-1322

46. Rakotondrabe M, Haddab Y, Lutz P (2009) Development, modeling, and control of a micro-/nanopositioning 2-DOF stickslip device. IEEE/ASME Trans Mechatron (T-mech) 14(6):733745

47. Rakotondrabe M, Haddab Y, Lutz P (2009) Quadrilateral modelling and robust control of a nonlinear piezoelectric cantilever. IEEE Trans Control Syst Technol (T-CST) 17(3):528-539

48. Rakotondrabe M, Clévy C, Lutz P (2010) Complete open loop control of hysteretic, creeped and oscillating piezoelectric cantilever. IEEE Trans Autom Sci Eng (T-ASE) 7(3):440-450

49. Rakotondrabe M, Ivan I, Khadraoui S, Clévy C, Lutz P, Chaillet N (2010) Dynamic displacement self-sensing and robust control of cantilevered piezoelectric actuators dedicated to microassembly tasks. In: IEEE/ASME AIM (International conference on intelligent materials). Montreal, Canada, pp 557-562

50. Rakotondrabe M, Rabenorosoa K, Agnus J, Chaillet N (2011) Robust feedforward-feedback control of a nonlinear and oscillating 2-DOF piezocantilever. IEEE Trans Autom Sci Eng (T-ASE) 8(3):506-519

51. Tamadazte B, Dembélé S, Fort-Piat NL (2008) A multiscale calibration of a photon video microscope for visual servo control: application to micromanipulation. In: ROSE 2008-IEEE international workshop on robotic and sensors environments, Ottawa, Canada, 17-18 October

52. Tamadazte B, Dembele S, Lefort-Piat N (2009) A multicale calibration of a photon video microscope for visual servo control. Sens Transducers J 5:37-52

53. Tamadazte B, Marchand E, Dembele S, LeFort-Piat N (2010) Cad model based tracking and 3d visual-based control for MEMS microassembly. Int J Rob Res 29(11):14161437

54. Zhou Y, Nelson BJ (1999) Calibration of a parametric model of an optical microscope. Opt Eng 38(12):19891995 